\title{
Box-Wilson Design for Optimization of in vitro Levan Production and Levan Application as Antioxidant and Antibacterial Agents
}

\author{
Rukman Hertadi $^{*}$, Nur Umriani Permatasari ${ }^{2}$, and Enny Ratnaningsih ${ }^{1}$ \\ ${ }^{1}$ Biochemistry Research Division, Faculty of Mathematics and Natural Sciences, Bandung \\ Institute of Technology, Indonesia; ${ }^{2}$ Chemistry Department, Faculty of Mathematics \\ and Natural Sciences, Hasanuddin University, Indonesia
}

Received 28 April 2020; accepted 7 September 2020; published online 27 December 2020

\begin{abstract}
Background: Levan or fructan, a polysaccharide of fructose, is widely used in various commercial industries. Levan could be produced by many organisms, including plants and bacteria. The cloning of the gene from Bacillus licheniformis, which expressed levansucrase in Escherichia coli host, was carried out successfully. In the present study, we performed the in vitro production of levan and analyzed its potential application as antibacterial and antioxidant agents. Methods: In vitro levan production catalyzed by heterologous-expressed levansucrase Lsblbk1 and Lsbl-bk2 was optimized with BW design. The antibacterial activity of the produced levan was carried out using agar well diffusion method, while its antioxidant activity was tested by free radical scavenging assays. Results: The optimum conditions for levan production were observed at $36{ }^{\circ} \mathrm{C}$ and $\mathrm{pH} 7$ in $12 \%(\mathrm{w} / \mathrm{v})$ sucrose for levansucrase Lsbl-bk1, while the optimum catalysis of levansucrase Lsbl-bk2 was obtained at $32{ }^{\circ} \mathrm{C}$ and pH 8 in the same sucrose concentration. The in vitro synthesized levan showed an antibacterial activity within a concentration range of $10-20 \%(\mathrm{w} / \mathrm{v})$ against Staphylococcus aureus, E. coli, and Pseudomonas aeruginosa. The same levan was also able to inhibit the DPPH radical scavenging activity with the antioxidant strength of $75 \%$ compared to ascorbic acid inhibition. Conclusion: Our study, therefore, shows that the optimized heterologous expression of levansucrases encoded by Lsbl-bk1 and Lsbl-bk2 could open the way for industrial levan production as an antibacterial and antioxidant agent. DOI: 10.52547/ibj.25.3.202
\end{abstract}

Keywords: Antioxidants, Fructans, In vitro technique, Levan

Corresponding Author: Rukman Hertadi

Biochemistry Research Division, Faculty of Mathematics and Natural Sciences, Bandung Institute of Technology, Indonesia;

Tel.: (+62-22) 2502103; Fax: (+62-22) 2504154; E-mail: rukman@chem.itb.ac.id

\section{INTRODUCTION}

$\mathrm{L}$ evansucrase, an enzyme belonging to the fructosyltransferase class, is secreted by several organisms, including plants and bacteria, and is widely distributed in both Gram-positive and Gramnegative bacteria ${ }^{[1]}$. Levansucrase from Gram-positive bacteria is secreted as a specific extracellular enzyme by two-step mechanisms as the enzyme possesses signal peptides cleaved after the carboxyl-terminal alanine during its export from the cytoplasmic to the outside of the cell ${ }^{[2-4]}$. In contrast, levansucrase from Gram-negative bacteria is fully secreted into its medium by a signal peptide-independent pathway involving the formation of an intermediate $\mathrm{N}$-terminal protected amino acid in the periplasmic loop ${ }^{[5,6]}$. Levansucrase (EC 2.4.1.10) cleaves the $\beta-1,2-$ glycosidic bond of sucrose and transfers the resulted fructosyl unit to numerous acceptor molecules, such as the short-chain acyl alcohols or mono- and disaccharides $^{[7]}$, as well as catalyzes the conversion of sucrose to fructan polymer. Levansucrase structure is

List of Abbreviations:

BW, Box-Wilson; CCD, central composite design; DPPH, 1,1-diphenyl-2-picrylhydrazyl; DTG, differential thermal analysis; FTIR, Fourier Transform Infrared; $\mathbf{I C}_{50}$, The half maximal inhibitory concentration; IPTG, isopropyl- $\beta$-D-thiogalactopyranoside; LB, Luria Bertani; NA, bactonutrient agar; NMR, Nuclear Magnetic Resonance; RSM, response surface methodology; SEM, scanning electron microscopy; TG, thermogravimetric 
supposed to be cell-wall anchoring motifs in their Cterminal domains, which are involved in the proteolysis $^{[8,9]}$.

Levan is one of the fructose polymers (fructan) linked by the $\beta$-2,6-fructofuranosidic bond, synthesized in transfructosylation reaction, and catalyzed by levansucrase using sucrose as a substrate ${ }^{[10,11]}$. Fructan, as a product of fructosyltransferase activity, can be obtained from various sources with different chemical compositions, molecular weights, and structures ${ }^{[12,13]}$. Levan is naturally synthesized by several flowering plant species, some bacteria, and fungi ${ }^{[14,15]}$. Due to the unique characteristics, levans are being used in various industries, including food, cosmetic, and medicinal products. Levan is nontoxic and highly soluble in water and possesses low viscosity, strong adhesivity, and film-forming ability, as well as compatiblility with salts and surfactants, heatstability, acid and alkali adaptability, biodegradablility, and biocompatiblility to other substances ${ }^{[16-18]}$. In comparison to the levan product in plants, those synthesized by bacteria often have a higher degree of polymerization ${ }^{[19]}$. Bacterial levans contains around $10^{3}-10^{4}$ fructosyl units, whereas plant levans consist of about 10-200 fructosyl units ${ }^{[20]}$.

As the microbial levansucrase generates more branched levans, the levan products have larger molecular weight $\left(2-100 \times 10^{6} \mathrm{Da}\right)$ and more extensively branched when compared to levans from plants (2000$3300 \mathrm{Da})^{[16,21,22]}$. Furthermore, plants make their levans in vacuoles, while bacteria produce them extracellularly ${ }^{[23]}$. Levan, commonly found as a microbial exopolysaccharide, is produced by hydrolysis and transfructosylating activities of levansucrase ${ }^{[24]}$. Production of microbial levansucrase is greatly affected by fermentation parameters, such as sucrose concentration, nutrients sources, $\mathrm{pH}$, temperature, time of cultivation, agitation, and aerations rates $^{[19,25,26]}$. Currently, optimization of levan productions is a very interesting field of research and is important in developing an efficient and cost-effective biopolymer production process ${ }^{[24]}$. Since levan is a non-toxic polymer and can easily be synthesized in vitro, many researchers have focused on levan production using bacterial native extracellular levansucrase $^{[27]}$. In addition, the data on levansucrase gene and protein structures are available ${ }^{[19]}$. However, levan production using recombinant levansucrase is rarely been reported.

The wild types Bacillus licheniformis BK1 and BK2 are Gram-positive halophilic bacteria, which were isolated from Bledug Kuwu mud crater, Central Java, Indonesia. In our previous study, we successfully constructed the expression vectors pET-lsbl-bkl and pET-lsbl-bk2 for high-level expression of levansucrase production $^{[28]}$. In the present study, we aimed to investigate and optimize levan production catalyzed by recombinant levansucrase from $B$. licheniformis BK1 and BK2 expressed by pET-lsbl-bkl and pET-lsbl-bk2 constructs in Escherichia coli host. Herein, we report the optimum condition of levan production by two recombinant enzymes. The potential uses of levan, as an antioxidant and antibacterial agent, were also studied.

\section{MATERIALS AND METHODS}

\section{Strains, plasmids, and culture condition}

E. coli BL21 (DE3) pLysS (our collection), as the expression host and plasmids pET-30a(+) (Invitrogen, USA), pET-lsbl-bk1 (GenBank: MF774877.1), and pET-lsbl-bk2 (GenBank: MF774878.1) as expression vectors were used in recombinant production of target enzyme Staphylococcus aureus, E. coli, and Pseudomonas aeruginosa (obtained from Microbiology Study Program, Universitas Hasanuddin, Indonesia) were used in antibacterial assays. The $E$. coli strains were grown in LB medium containing $1 \%$ $(\mathrm{w} / \mathrm{v})$ tryptone (Liofilchem, Italy), $0.5 \%(\mathrm{w} / \mathrm{v})$ yeast extract (Liofilchem), and $1 \%(\mathrm{w} / \mathrm{v}) \mathrm{NaCl}$ (Merck, Germany). Kanamycin (Bio Basic, USA) was $\mathrm{u}$ for selecting recombinant $E$. coli cells. Chemicals employed in this study were IPTG (Thermo Fisher Scientific, USA), 3,5-dinitrosalicyclic acid (Sigma Aldrich, USA), sucrose, $\mathrm{Na}_{2} \mathrm{HPO}_{4}, \mathrm{NaH}_{2} \mathrm{PO}_{4} \cdot \mathrm{H}_{2} \mathrm{O}$, ethanol, phenol, $\mathrm{H}_{2} \mathrm{SO}_{4} 97 \%$, DPPH, and ascorbic acid (Merck).

\section{High level in vitro synthesis of levan}

The in vitro levan synthesis was developed in twostage processes. The first process was the heterologous overexpression of levansucrase gene cloned (pET-lsbl$b k 1$ and pET-lsbl-bk2) in E. coli BL21 (DE3) pLysS host cell to produce levansucrase, which its conditions had been optimized in our previous research ${ }^{[29]}$. The second process was the catalytic reaction in a sucrose medium employing the produced levansucrase to enhance levan production. The optimizations of in vitro levan were performed using the RSM approach $^{[29,30]}$

\section{Heterologous expression of $B$. licheniformis levansucrase}

A single colony of E. coli BL21 (DE3) pLysS cells carrying pET-lsbl-bkl was inoculated into a 5-mL LB medium containing $50 \mu \mathrm{g} / \mathrm{mL}$ of kanamycin and $0.6 \%$ (w/v) $\mathrm{NaCl}$. The culture was grown at $37{ }^{\circ} \mathrm{C}$ overnight. Then $2 \mathrm{~mL}$ of this overnight culture was inoculated into $100 \mathrm{~mL}$ of a fresh LB medium containing kanamycin and $\mathrm{NaCl}$, incubated at $37{ }^{\circ} \mathrm{C}$ with aeration until the $\mathrm{OD}_{600}$ reached 0.6-1. The expression of 
levansucrase was induced by IPTG $(0.6-\mathrm{mM})$, and the culture was further incubated at $42{ }^{\circ} \mathrm{C}$ for 4 hours. Different conditions were performed for $\mathrm{pET}-l s b l-b k 2$, including $1.1 \%(\mathrm{w} / \mathrm{v}) \mathrm{NaCl}, 0.7 \mathrm{mM}$ of IPTG, and 40 ${ }^{\circ} \mathrm{C}$ incubation temperature. The expressed enzyme is known to be secreted into the medium ${ }^{[28]}$. Therefore, the supernatant of the culture, i.e. the levansucrase crude extract, was collected by centrifugation at 6,082 $\times \mathrm{g}$ at $4{ }^{\circ} \mathrm{C}$ for $15 \mathrm{~min}$. The obtained crude extracts were used in experiments to optimize the in vitro levan production by RSM.

\section{Experimental design}

The RSM was applied to search for the optimum condition of levan production catalyzed by levansucrase Lsbl-bk2 ${ }^{[29]}$. BW design was also used to optimize the in vitro levan production catalyzed by Lsbl-bk1. BW design and CCD are experimentally efficient technique for our study to develop a predictive model using experimental variables on in vitro levan production. In this design, the following three parameters were applied: the temperature of incubation $\left(X_{1}\right)$ between $20{ }^{\circ} \mathrm{C}$ to $54{ }^{\circ} \mathrm{C}, \mathrm{pH}\left(X_{2}\right)$ from 4 to 10 , and sucrose concentration $\left(X_{3}\right)$ from $5 \%$ to $20 \%(\mathrm{w} / \mathrm{v})$, as presented in Tables 1 and 2 . The design was made up of $\mathrm{BW}$ full $2^{3}$ factorial with eight cube points, augmented with five center points and six-star points. Accordingly, the total runs included 20 experiments. Levan concentration $(Y)$ was considered as a dependent (response) variable. To estimate the optimal point and generate the contour plots, a second-order polynomial function was fitted to the experimental results. The predicted values of the model were validated by experiments performed in five replicates and compared with the model predicted values. The Minitab statistical software (version 18) was used for the experimental designs and regression analysis of the experimental data.

\section{In vitro levan production and determination of levan concentration}

The in vitro levan synthesis was conducted with various conditions (Table 1) by mixing $8 \mathrm{~mL}$ of levansucrase fresh crude extract with $8 \mathrm{~mL}$ of phosphate buffer containing sucrose substrate, filtered through a $0.45-\mu \mathrm{m}$ filter before loading with enzyme crude extract. The reaction mixtures were incubated at the desired temperature for 24 hours, stopped by heating at $80-100{ }^{\circ} \mathrm{C}$ for $5 \mathrm{~min}$, and cooled down to room temperature. The suspensions were then centrifuged at $6,082 \times \mathrm{g}$ at $25{ }^{\circ} \mathrm{C}$ for $10 \mathrm{~min}^{[30]}$. The concentration of the produced levan in the supernatants was determined by colorimetric phenolic-sulfuric method at $490 \mathrm{~nm}$ using fructose as a standard via determining the amount of sugar produced from sucrose hydrolysis by levansucrase ${ }^{[31,32]}$. Briefly, 450 $\mu \mathrm{L}$ of levan solution was transferred into a tube, and 50 $\mu \mathrm{L}$ of $5 \%(\mathrm{w} / \mathrm{v})$ phenol solution was added. The mixture was then vortexed to homogenize. In the next step, $500 \mu \mathrm{L}$ of concentrated sulfuric acid was added rapidly and carefully. The tube was allowed to stand on ice bath for 5 min shaken, and placed in a $90{ }^{\circ} \mathrm{C}$ water bath for $5 \mathrm{~min}$ to stop the reaction. The mixture was cooled down to room temperature before reading the absorbance of the final yellow-orange color product at $490 \mathrm{~nm}$.

\section{Levan extraction}

The levan was extracted from the supernatant through the precipitation by adding three volumes of cold ethanol $(3: 1 \mathrm{v} / \mathrm{v})$ at $4{ }^{\circ} \mathrm{C}$ overnight. The precipitate was recovered by centrifugation at $6,082 \times \mathrm{g}$ at $4{ }^{\circ} \mathrm{C}$ for $20 \mathrm{~min}$. To remove impurities, the precipitate was washed twice with ethanol $96 \%$ and once with deionized water, then freeze-dried for about 2 to 4 hours. The obtained levan was used for further analysis, such as morphological characterization, structure identification, thermal stability determination, and bioactivity.

\section{Levan analysis \\ Characterization of levan}

The morphology of the solid synthesized levan was analyzed by SEM (JEOL JSM 6510 LA, Japan), and its structure was characterized using FTIR (Shimadzu IR Prestige-21, Japan) and NMR spectroscopy (NMR spectrometer, Agilent $500 \mathrm{MHZ}$, USA) to obtain ${ }^{1} \mathrm{H}$ NMR and ${ }^{13}$ C-NMR spectra. Besides, the characterization of levan thermal stability was determined under a nitrogen atmosphere using thermal gravimetric analysis (TG/DTG, Hitachi STA7300, USA).

\section{Antioxidant activity of levan}

Antioxidant activity of levan was tested by DPPH free radicals scavenging assays ${ }^{[33,34]}$ using ascorbic acid as a standard. A fresh solution of DPPH was prepared by dissolving solid DPPH in ethanol absolute to obtain $0.5 \mathrm{mM}$ of DPPH concentration. Ascorbic acid solutions were prepared in various concentrations (30, 120, 240, 420, 600, 960, and $1200 \mu \mathrm{g} / \mathrm{mL})$, and levan solutions were prepared at the concentrations of $30,250,500,1250,2500,3500,4500$, and 5000 $\mu \mathrm{g} / \mathrm{mL}$. Afterward, $250 \mu \mathrm{L}$ of DPPH solution $(0.5 \mathrm{mM})$ was added to $1.0 \mathrm{~mL}$ of the tested solution, which was then shaken vigorously to become homogeneous and incubated in the dark at room temperature for 30 minutes. The absorbance was read at $514 \mathrm{~nm}$. Ethanol was utilized as a control solution. The percentage of inhibition was calculated using the following formula: 
Table 1. The CCD experimental design for in vitro levan production catalyzed by Lsbl-bk1

\begin{tabular}{lrrrrc}
\hline \multirow{2}{*}{ Parameters } & \multicolumn{5}{c}{ Levels } \\
\cline { 2 - 6 } & $\mathbf{- 1 , 6 8 2}$ & \multicolumn{1}{c}{$\mathbf{1}$} & \multicolumn{1}{c}{$\mathbf{0}$} & $\mathbf{+ 1}$ & $\mathbf{+ 1 , 6 8 2}$ \\
\hline Temperature $\left({ }^{\circ} \mathrm{C}\right)$ & 20.0 & 27.5 & 37.0 & 47.4 & 54.0 \\
Sucrose concentration $(\% \mathrm{w} / \mathrm{v})$ & 5.0 & 8.0 & 12.5 & 16.9 & 20.0 \\
$\mathrm{pH}$ & 4.0 & 5.2 & 7.0 & 8.7 & 10.0 \\
\hline
\end{tabular}

$\%$ inhibition $=$

$\underline{\text { The absorbance of the control-Absorbance of the sample }} \times 100$

The concentration of the sample with $\mathrm{IC}_{50}$ was calculated from the graph of $\%$ inhibition vs. sample concentration.

\section{Antibacterial activity of levan}

The antibacterial activity of levan was assessed against three species, namely $E$. coli, S. aureus, and $P$. aeruginosa. The test was carried out using agar well diffusion method utilizing a metal cup with a diameter of $6 \mathrm{~mm}$ and height of $10 \mathrm{~mm}$. In this experiment, $0.5 \%(\mathrm{~b} / \mathrm{v})$ NA supplemented with $0.3 \%(\mathrm{~b} / \mathrm{v})$ beef extract and $0.5 \%(\mathrm{~b} / \mathrm{v})$ peptone was used. Also, $1 \mathrm{~mL}$ of the fresh liquid culture containing about $10^{5}-10^{6}$ CFU was spread onto the NA solid medium, where the well was made using a metal cup, which was then filled with $0.2 \mathrm{~mL}$ levan solution ( $10 \%$ and $20 \% \mathrm{w} / \mathrm{v})$. The system was incubated at $37{ }^{\circ} \mathrm{C}$ for $24 \mathrm{~h}$, and the antimicrobial activity was detected by measuring the inhibitory clear zones around the well ${ }^{[35,36]}$.

\section{RESULTS}

\section{Optimization of high level in vitro levan synthesis}

The in vitro synthesis of levan was carried out by levansucrase utilizing sucrose as a substrate. The conditions of in vitro levan production were optimized to achieve high efficiency and high yield of levan through RSM. Three parameters, the temperature of incubation $\left(X_{1}\right), \mathrm{pH}$ of the medium $\left(X_{2}\right)$, and sucrose concentration $\left(X_{3}\right)$, influencing the in vitro levan production catalyzed by Lsbl-bk1 were treated as independent variables. The values of the obtained response under different experimental conditions of BW $2^{3}$ factorial CCD are listed in Table 2. Optimization of in vitro levan production catalyzed by Lsbl-bk2 was not described as it had been reported in our previous study ${ }^{[29]}$. The results of CCD were fitted into second-order polynomial equation (equation 2) for the prediction of response on the basis of coded value. $Y=$

$-326.1+8.665\left(X_{1}\right)+58.47\left(X_{2}\right)+$ $10.43\left(X_{3}\right)-0.12\left(X_{1}\right)^{2}-4.19\left(X_{2}\right)^{2}-0.47\left(X_{3}\right)^{2}-$

$$
0.04\left(X_{1} X_{2}\right)+0.01\left(X_{1} X_{3}\right)+0.06\left(X_{2} X_{3}\right)
$$

Equation 2 reveals the relationship between levan concentration, as a dependent variable, obtained from linear or quadratic of the three independent variables. Model significance and role of each variable were evaluated using ANOVA, and the results were presented in Table 3. The mathematical model obtained (Equation 2 ) resulting $p<0.05$, indicated statistically significant of this model. The ANOVA of the regression model gave both $R^{2}$ and adjusted $R^{2}$ values close to 1.00 , further confirming that the model was highly significant to predict the response. Besides, the quadratic model was statistically significant for the description of levan yield where the $p$ value is 0.000 , which is less than 0.05 . It can be seen from Table 3 that the linear and quadratic terms of regression

Table 2. BW $2^{3}$ factorial experimental results of in vitro levan production

\begin{tabular}{ccccc}
\hline Run & $\begin{array}{c}\text { Temp } \\
\left({ }^{\circ} \mathbf{C}\right)\end{array}$ & $\mathbf{p H}$ & $\begin{array}{c}\text { Sucrose } \\
\text { concentration } \\
(\boldsymbol{\%} \text { w/v })\end{array}$ & $\begin{array}{c}\text { Observed levan } \\
\text { concentration } \\
(\mathbf{m g} / \mathbf{m L})\end{array}$ \\
\hline 1 & 54.0 & 7.0 & 12.5 & 58 \\
2 & 37.0 & 7.0 & 12.5 & 96 \\
3 & 37.0 & 4.0 & 12.5 & 63 \\
4 & 47.1 & 8.8 & 17.0 & 61 \\
5 & 37.0 & 7.0 & 12.5 & 96 \\
6 & 37.0 & 7.0 & 5.0 & 76 \\
7 & 26.9 & 5.2 & 17.0 & 61 \\
8 & 37.0 & 7.0 & 12.5 & 97 \\
9 & 47.1 & 5.2 & 8.0 & 64 \\
10 & 26.9 & 5.2 & 8.0 & 64 \\
11 & 26.9 & 8.8 & 8.0 & 64 \\
12 & 37.0 & 10.0 & 12.5 & 51 \\
13 & 47.1 & 8.8 & 8.0 & 61 \\
14 & 37.0 & 7.0 & 12.5 & 96 \\
15 & 20.0 & 7.0 & 12.5 & 64 \\
16 & 47.1 & 5.2 & 17.0 & 63 \\
17 & 37.0 & 7.0 & 20.0 & 60 \\
18 & 37.0 & 7.0 & 12.5 & 96 \\
19 & 26.9 & 8.8 & 17.0 & 63 \\
20 & 37.0 & 7.0 & 12.5 & 96 \\
\hline
\end{tabular}

Temp, temperature 
Table 3. Analysis of variance for in vitro levan production catalyzed by Lsbl-bk1 $(Y)$ as the function of temperature $\left(X_{1}\right), \mathrm{pH}\left(X_{2}\right)$, and sucrose concentration $\left(X_{3}\right)$

\begin{tabular}{lccccc}
\hline Source & $\begin{array}{c}\text { Sum of } \\
\text { squares }\end{array}$ & $\begin{array}{c}\text { Degrees of } \\
\text { freedom }\end{array}$ & $\begin{array}{c}\text { Mean } \\
\text { square }\end{array}$ & F-value & $\boldsymbol{p}$ value \\
\hline Model & 5018.78 & 9 & 557.64 & 51.42 & 0.000 \\
Linear & 121.89 & 3 & 40.63 & 3.75 & 0.049 \\
$X_{1}$ & 9.33 & 1 & 9.33 & 0.86 & 0.375 \\
$X_{2}$ & 34.14 & 1 & 34.14 & 3.15 & 0.106 \\
$X_{3}$ & 78.43 & 1 & 78.43 & 7.23 & 0.023 \\
Square & 4889.84 & 3 & 1629.95 & 150.31 & 0.000 \\
$X_{1} X_{1}$ & 2017.58 & 1 & 2017.58 & 186.06 & 0.000 \\
$X_{2} X_{2}$ & 2558.31 & 1 & 2558.31 & 235.92 & 0.000 \\
$X_{3} X_{3}$ & 1245.50 & 1 & 1245.50 & 114.86 & 0.000 \\
2 -way interaction & 7.05 & 3 & 2.35 & 0.22 & 0.883 \\
$X_{1} X_{2}$ & 4.16 & 1 & 4.16 & 0.38 & 0.550 \\
$X_{1} X_{3}$ & 1.09 & 1 & 1.09 & 0.10 & 0.758 \\
$X_{2} X_{3}$ & 1.80 & 1 & 1.80 & 0.17 & 0.692 \\
Error & 108.44 & 10 & 10.84 & & \\
Lack-of-fit & 107.82 & 5 & 21.56 & 174.01 & 0.000 \\
Pure error & 0.62 & 5 & 0.12 & & \\
Total & 5127.22 & 19 & & & \\
\hline$R^{2}=0.9789 ; R^{2}(a d j)$ & 0.9598 & & & & \\
\hline
\end{tabular}

$R^{2}=0.9789 ; R^{2}$ (adjusted) $=0.9598$

coefficients on sucrose concentration $\left(\mathrm{X}_{3}\right)$ were significantly influenced by the in vitro levan production because the probability value is smaller than 0.05 .

The three-dimensional response surface described by the contour plots model is presented in Figure 1. The highest levan concentration is predicted to be at $36{ }^{\circ} \mathrm{C}$, $96.268 \mathrm{mg} / \mathrm{mL}$ levan. Five experiment replicates were then performed under this predicted optimum condition, and the obtained levan concentration was $96.117 \mathrm{mg} / \mathrm{mL}$ on average.

\section{Analysis of levan structure}

The structure of levan was verified by FTIR and NMR, as presented in Figure 2. In FTIR, absorption characteristic of levan (Fig. 2A) was attributed by the $\mathrm{O}-\mathrm{H}$ stretching at around $3447-3414 \mathrm{~cm}^{-1}, \mathrm{C}-\mathrm{H}$ stretching at around $2931.80 \mathrm{~cm}-1$, and $\mathrm{C}=\mathrm{O}$ stretching at $1658.78 \mathrm{~cm}-1$. The fingerprint $\mathrm{pH} \mathrm{7, \text {and }}$ $12 \%(\mathrm{w} / \mathrm{v})$ of sucrose, which produced spectrum between $1271.01 \mathrm{~cm}^{-1}$ and $925.83 \mathrm{~cm}^{-1}$ corresponded to carbohydrate molecules and related to overlapping signals of glycosidic (C-O-C) stretching. The levan
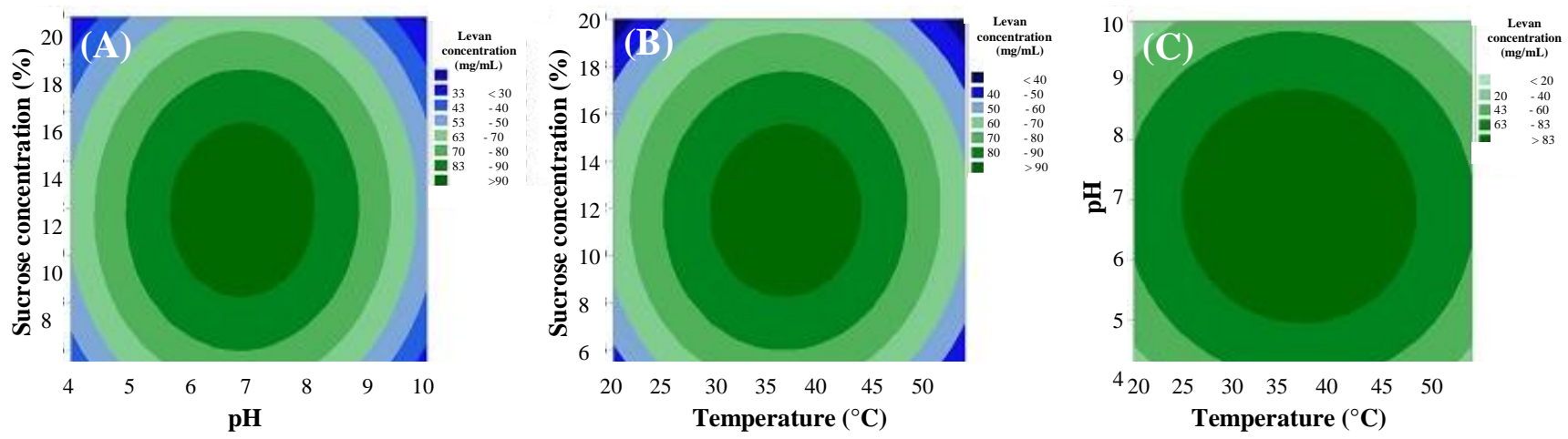

Fig. 1. Contour plots predicting in vitro levan production as the function of $\mathrm{pH}$ and sucrose concentration (A), temperature and sucrose concentration (B), and temperature and $\mathrm{pH}(\mathrm{C})$. 


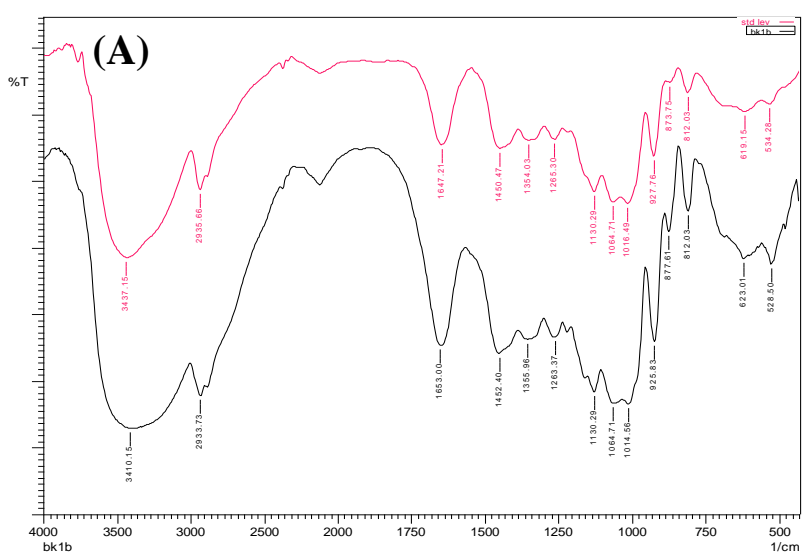

(B)

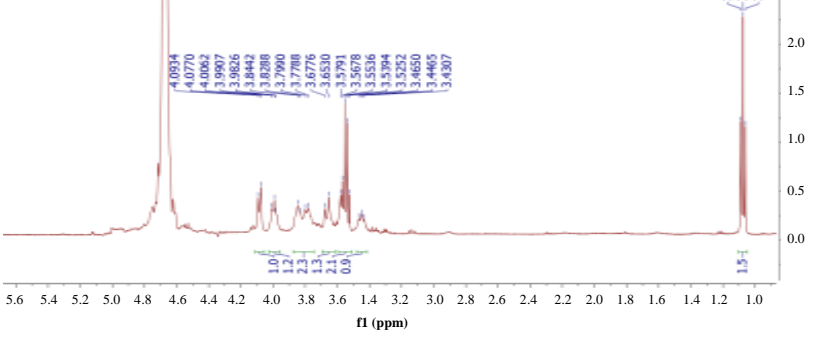

(C)

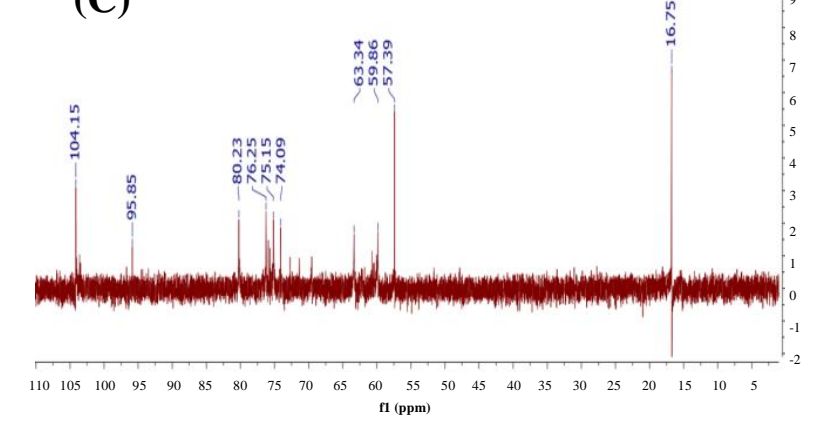

Fig. 2. Analysis of the produced levan catalyzed by Lsbl-bk1: (A) FTIR spectrum of levan (black line) compared with levan standard from E. herbicola (red line), (B) levan ${ }^{1} \mathrm{H}-\mathrm{NMR}$ spectrum, and (C) levan ${ }^{13} \mathrm{C}-\mathrm{NMR}$ spectrum.

spectra, ${ }^{1} \mathrm{H}-\mathrm{NMR}$, and ${ }^{13} \mathrm{C}-\mathrm{NMR}$ can be seen in Figures $2 \mathrm{~B}$ and $2 \mathrm{C}$. The levan ${ }^{1} \mathrm{H}-\mathrm{NMR}$ spectrum exhibited the signal characteristic between 3.4 and 4.3 ppm, associated with sugar protons (Fig. 2B). The six broad resonance signals of levan ${ }^{13} \mathrm{C}$-NMR spectrum at 104.1 (C2), 80.2 (C5), 76.2 (C3), 75.1 (C4), 63.3 (C6), and $59.8(\mathrm{C} 1) \mathrm{ppm}$ corresponded to the carbon of $\beta$ fructofuranose, confirming that levan has successfully been synthesized.

\section{Morphology analysis}

The in vitro levan product catalyzed by Lsbl-bk1 and Lsbl-bk2 were extracted with ethanol. The resulted levan showed different solid appearances, and then SEM was examined. The product of Lsbl-bk1 appeared as a white granule (Fig. 3A) with irregular circular pores, while the Lsbl-bk2 product showed yellow solid and a rather sticky texture (Fig. 3B), with a sheetshaped solid without any pores. These morphology differences might be due to different synthesis conditions, particularly the $\mathrm{pH}$, which would influence the morphological characteristic of the synthesis polymer ${ }^{[29]}$.

\section{TG and DTG analysis}

TG analysis and DTG profiles were used to investigate the thermal stability of the produced levan. The obtained thermograms of the in vitro produced levan catalyzed by Lsbl-bk1 and Lsbl-bk2 are presented in Figure 4, showing three stages of levan mass reduction at $0-100{ }^{\circ} \mathrm{C}, 100-200{ }^{\circ} \mathrm{C}$, and $200-300$ ${ }^{\circ} \mathrm{C}$. The first region, $0-100{ }^{\circ} \mathrm{C}$, is attributed to water and ethanol evaporation. Both levans attained their weight in the second region, $100-200{ }^{\circ} \mathrm{C}$, indicating its thermal stability. The third region, $200-300{ }^{\circ} \mathrm{C}$, which showed around $50 \%$ of mass reduction, might be corresponded to levan degradation. The DTG curves demonstrate that the main peak of levan degradation occurred at $211{ }^{\circ} \mathrm{C}$ and $208{ }^{\circ} \mathrm{C}$ for levan of Lsbl-bk1 and Lsbl-bk2, respectively.

\section{Antioxidant activity}

The antioxidant activity of the produced levan catalyzed by Lsbl-bk1 and Lsbl-bk2 was evaluated by DPPH free radical scavenging method. The results exhibited that the percentage activity of both levans is at the concentration of $30-1200 \mu \mathrm{g} / \mathrm{mL}$, which could inhibit around 55\% DPPH activity compared to ascorbic acid, which effectively inhibited up to $76 \%$ at the same concentration (Fig. 5). The scavenging activities of both levans directly increased to $75 \%$ if the concentration increased up to $5 \mathrm{mg} / \mathrm{mL}$.

\section{Antibacterial activity}

Antibacterial activity of the levan products was studied against $E$. coli, $S$. aureus, and $P$. aeruginosa. The results are depicted in Figure 6. The antibacterial activities were observed as a clear zone around the cup filled with levan. It can be seen in the Figure that both levans possessed antibacterial activity. Levan produced by Lsbl-bk1 catalysis showed the highest activity against $S$. aureus $(12-16 \mathrm{~mm})$, whereas those catalyzed by Lsbl-bk2 had the highest activity against $E$. coli $(15-16 \mathrm{~mm})$ and $P$. aeruginosa $(14-16 \mathrm{~mm})$. The appearance of the inhibition zone was not broad and not strong enough to necessarily kill the bacteria, indicating that levan owes a bacteriostatic effect on these tested bacteria. 

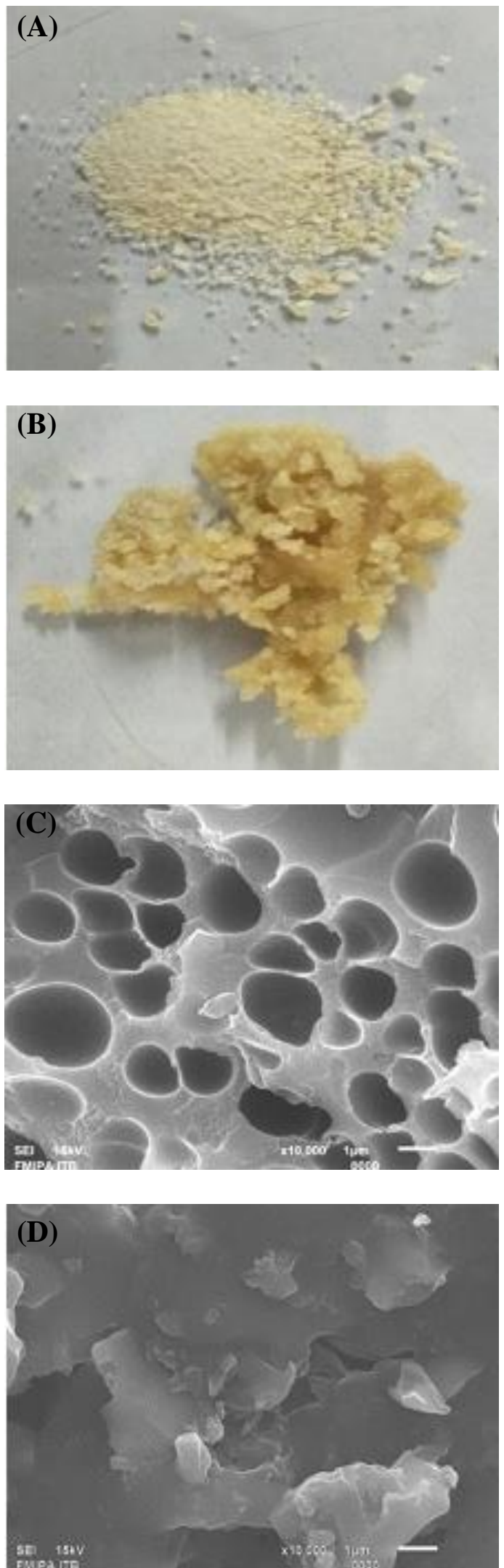

Fig. 3. The morphological characteristic of solid produced levan catalyzed by (A) Lsbl-bk1 and (B) Lsbl-bk2 and the SEM image of levan catalyzed by (C) Lsbl-bk1 and (D) Lsbl-bk2.

\section{DISCUSSION}

BW design has been proved to be an efficient technique for optimization of the in vitro levan production catalyzed by levansucrase Lsbl-bk1, using three variables (temperature, $\mathrm{pH}$, and sucrose concentration). The interaction between the three tested independent variables revealed no significant effect on in vitro levan production, as indicated by the $p>0.05$ (Table 3). The same result was also achieved from the in vitro levan production catalyzed by levansucrase Lsbl-bk $2^{[29]}$. It is of advantageous that the three studied variables are non-interacting one to the other; hence, the changes of one variable would minimally affect the others.

Our study indicated that the optimum condition for the in vitro levan synthesis catalyzed by Lsbl-bk1 was at $36^{\circ} \mathrm{C}, \mathrm{pH} 7$, and $12 \%(\mathrm{w} / \mathrm{v})$ sucrose, while this condition for Lsbl-bk2 was at $32^{\circ} \mathrm{C}, \mathrm{pH} 8$, and $12 \%$ $(\mathrm{w} / \mathrm{v})$ sucrose $^{[29]}$. However, the in vitro levan synthesis by both levansucrases gave a similar high yield, which was about $95 \mathrm{mg} / \mathrm{mL}$. Lu et al. ${ }^{[30]}$ reported that the optimum condition for in vitro levan production catalyzed by recombinant levansucrase from $B$. licheniformis 8-37-0-1 occurred at $0.8 \mathrm{M}$ sucrose concentration (equivalent to $14 \% \mathrm{w} / \mathrm{v}$ ) in $\mathrm{pH} 6.5$ at 40 ${ }^{\circ} \mathrm{C}$ for 24 hours with a yield of $7.1 \mathrm{mg} / \mathrm{mL}$ levan. These dissimilarities might be due to the different environmental origins of $B$. licheniformis 8-37-0-1, which was isolated from the hydrothermal vent of Panarea Island (Italy) ${ }^{[37]}$, but our strain was obtained from Bledug Kuwu mud crater, Central Java, Indonesia. The in vitro production of levan in our research appeared to be more efficient, which resulted in higher levan yield at lower temperatures and lfor of in vitro levan production is more applicable and more feasible to industries.

The FTIR spectrum of levan catalyzed by Lsbl-bk1 was similar to that of levan from Erwinia herbicola ${ }^{[38]}$ and consistent with the spectrum of levan obtained by the catalysis of Lsbl-bk ${ }^{[29]}$. ${ }^{1} \mathrm{H}-\mathrm{NMR}$ and ${ }^{13} \mathrm{C}$-NMR spectra showed similar signals with the levan produced by Acetobacter xylinum NCIM2526 and Brenneria goodwinii ${ }^{[39,40]}$. The obtained FTIR and NMR patterns indicated that levan produced by the recombinant of $B$. licheniformis levansucrase represented $\beta-(2,6)$-levan polysaccharide.

The morphological properties of both synthetic levans were different due to variations in the synthesis of optimum conditions, especially $\mathrm{pH}$. Accordingly, the synthesis of $\mathrm{pH}$-responsive biopolymer was beneficial to develop preferred materials for drug delivery or other industrial desired materials ${ }^{[41]}$. Moreover, the thermal stability properties of levan produced were degraded at lower temperatures 

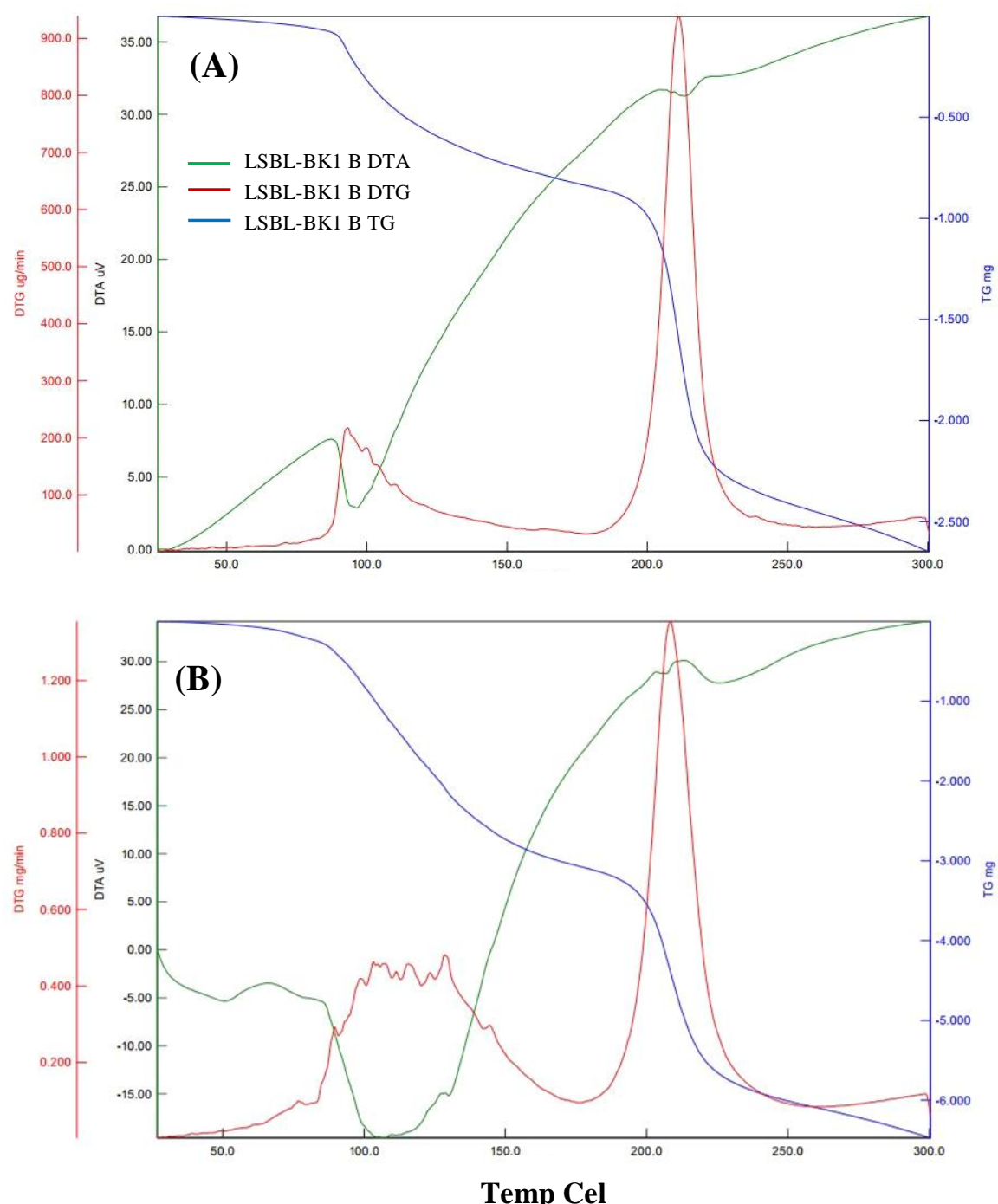

Fig. 4. TG and DTG curves of the produced levan catalyzed by (A) Lsbl-bk1 and (B) Lsbl-bk2. Blue, red, and green lines show TG, DTG, and DTA curves, respectively.

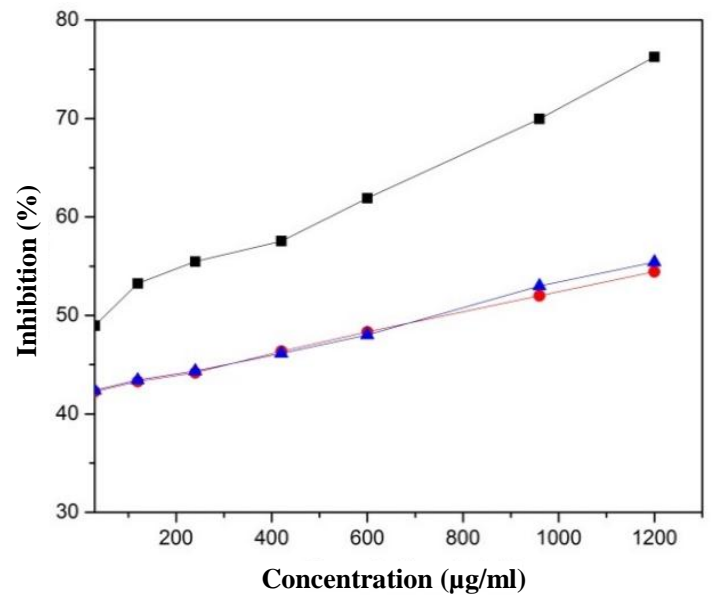

Fig. 5. Antioxidant activities of ascorbic acid (black rectangle), levan Lsbl-bk1 (red circle) and levan Lsbl-bk2 (blue triangle). $\left(208{ }^{\circ} \mathrm{C}\right.$ and $211{ }^{\circ} \mathrm{C}$ ) compared to other levans, such as levan produced by Zymomonas mobilis and Halomonas sp. AAD6 that degraded at $217^{\circ} \mathrm{C}$ and $253{ }^{\circ} \mathrm{C}$, respectively ${ }^{[42,43]}$.

The bioactivity of both levans has been tested in our study as antimicrobial and antioxidant agents. The antioxidant capacity of our levan was similar to that of Srikanth et al.' ${ }^{[16]}$ and Benattouche et al.' ${ }^{[44]}$ studies, in which the DPPH-scavenging effect increased with the elevation of levan concentration as exopolysaccharides. The scavenging ability of levan on DPPH radical might be due to the ability of hydroxyl group to donate its electron as hydrogen radical ${ }^{[27,34,45]}$. These results suggest that the antioxidant activity of both levans is relatively lower compared to ascorbic acid. However, it would be possible and might be beneficial to be used in biomedicine industries. Aside from that, 
E. coli
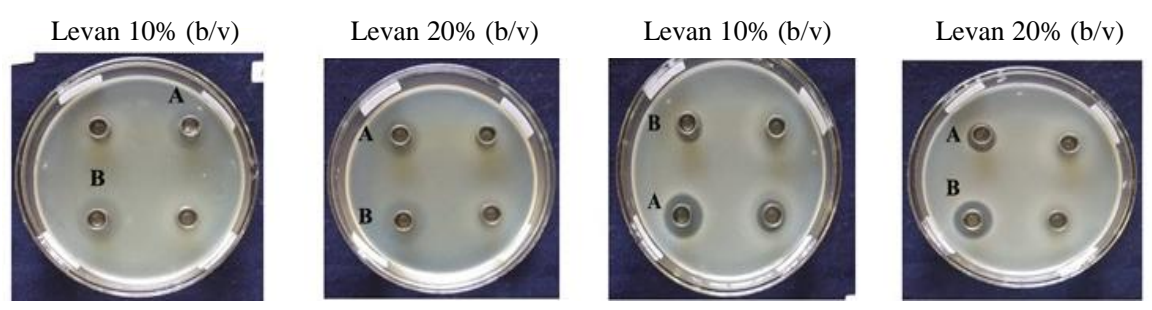

P. aeruginosa

Fig. 6. Growth inhibitions of E. coli, S. aureus, and P. aeruginosa in levan containing nutrient agar. A and B show produced levan catalyzed by Lsbl-bk1 and Lsbl-bk2, respectively.

both Lsbl-bk1 and Lsbl-bk2 levan products, as exoploysaccharides, have beneficial potency as an antibacterial agent. Previous studies have shown that exopolysachharides with antimicrobial activity could inhibit the growth of $S$. aureus, E. coli, and $P$. aeruginosa with an inhibition zone diameter about $15-20 \mathrm{~mm}^{[44,46]}$. It has also been assumed that exopolysaccharide levans can disrupt the bacterial cell wall integrity by blocking nutrients input ${ }^{[36,46]}$.

In summary, our preliminary research indicates that the produced levan possessed antioxidant and antibacterial activities; therefore, it is the potential to be used in food and pharmaceutical industries.

\section{ACKNOWLEDGEMENTS}

This research was supported by the Doctoral Research Grant from the Indonesian Ministry of Research and Technology with the contract number of 123/SP2H/PTNBH/DPRM 2018 and P3MI.

CONFLICT OF INTEREST. None declared.

\section{REFERENCES}

1. Malik A. Molecular cloning and in silico characterization of fructansucrase gene from Weissella confusa MBFCNC-2(1) isolated from local beverage. Asia-Pacific journal of molecular biology and biotechnology 2012; 20(1): 33-42.

2. Tjalsma H, Bolhius A, Jongbloed DH, Bron S, van Dijil JM. Signal peptide-dependent protein transport in Bacillus subtilis: a genome-based survey of the secretome. Microbiology and molecular biology reviews 2000; 64(3): 515-547.

3. Lanigan-Gerdes S, Briceno G, Dooley AN, Faull KF, Lazazzera BA. Identification of residues important for cleavage of the extracellular signal peptide CSF of Bacillus subtilis from its precursor protein. Journal of bacteriology 2008; 190(20): 6668-6675.
4. Simonen M, Palva I. Protein secretion in Bacillus species. Microbiology reviews 1993; 57(1): 109-137.

5. Jakob F, Meißner D, Vogel RF. Comparison of novel GH 68 levansucrases of levan-overproducing Gluconobacter species. Acetic acid bacteria 2012; 1: e2.

6. Van Hijum SA, Krajl S, Ozimek LK, Dijkhuizen L, van Geel-Schutten IG. Structure-function relationships of glucansucrase and fructansucrase enzymes from lactic acid bacteria. Microbiology and molecular biology reviews 2006; 70(1): 157-176.

7. Versluys M, Kirtel O, Öner ET, den Ende WV. The fructant syndrome: evolutionary aspects and common themes among plants and microbes. Plant, cell and environment 2018; 41(1): 16-38.

8. Desvaux M, Candela T, Serror P. Surfaceome and proteosurfaceome in parietal modern bacteria: focus on protein cell-surface display. Frontiers in microbiology 2018; 9: 100.

9. Hernandez L, Arrieta J, Menendez C, Vazquez R, Coego A, Suarez V, Selman G, Petit-Glatron MF, Chambert $\mathrm{R}$. Isolation and enzymic properties of levansucrase secreted by Acetobacter diazotrophicus SRT4, a bacterium associated with sugar cane. Biochemical journal 1995; 309(Pt 1): 113-118.

10. Wu FC, Chou SZ, Shih IL. Factors affecting the production and molecular weight of levan of Bacillus subtilis natto in batch and fed-batch culture in fermenter. Journal of the Taiwan institute chemical engineers 2013; 44(6): 846-853.

11. Seo JW, Song KB, Jang KH, Kim CH, Jung BH, Rhee SK. Molecular cloning of a gene encoding the thermoactive levansucrase from Rahnella aquatilis and its growth phase-dependent expression in Escherichia coli. Journal of biotechnology 2000; 81(1): 63-72.

12. Zong A, Cao H, Wang F. Anticancer polysaccharides from natural resources: A review of recent research. Carbohydrate polymers 2012; 90(4): 1395-1410.

13. Meyers MA, Chen PY, Lin AY, Seki Y. Biological materials: Structure and mechanical properties. Progress in materials science 2008; 53(1): 1-206.

14. Joaquim EO, Hayashi AH, Torres LMB, FigueiredoRibeiro RCL, Shiomi N, Sousa FS, Lago JHG, Carvalho MAM. Chemical structure and localization of levan, the predominant fructant type in underground systems of Gomphrenamarginata (Amaranthaceae). Frontiers in plant science 2018; 9: 1745. 
15. Álvaro-benito M, Sainz-Polo MA, González-Pérez D, González B, Plou FJ, Fernández-Lobato M, SanzAparicio J. Structural and kinetic insights reveal that the amino acid pair Gln-228/Asn-254 modulates the transfructosylating specificity of Schwanniomyces occidentalis $\beta$-fructofuranosidase, an enzyme that produces prebiotics. Journal of biological chemistry 2012; 287(23): 19674-19686.

16. Srikanth R, Reddy CHSSS, Siddartha G, Ramaiah MJ, Uppuluri KB. Review on production, characterization and applications of microbial levan. Carbohydrate Polymers 2015; 120: 102-114.

17. Divya JM, Sugumaran KR. Fermentation parameters and condition affecting levan production and its applications. Journal of chemical and pharmaceutical research 2015; 7(2): 861-865.

18. Szwengiel A, Wiesner M. Effect of metal ions on levan synthesis ef fi ciency and its parameters by levansucrase from Bacillus subtilis. International journal of biological macromolecules 2019; 128: 237-243.

19. Öner ET, Hernández L, Combie J. Review of levan polysaccharide: from a century experiences to future prospects. Biotecnology advances 2016; 34(5): 827-844.

20. Ritsema T, Smeekens S. Furctans: beneficial for plants and human. Current opinion in plant biology 2003; 6(3): 223-230.

21. Barone JR, Medynets M. Thermally processed levan polymers. Carbohydrate polymers 2007; 69(3): 554561.

22. Arvidson SA, Rinehart BT, Maria FG. Concentration regimes of solutions of levan polysaccharide from Bacillus sp. Carbohydr Polym 2006; 65: 144-149.

23. Velázquez-Hernández ML, Cha MP. Microbial fructosyltransferases and the role of fructans. Journal of applied microbiology 2009; 106: 1763-1778.

24. Belghith KS, Dahech I, Belghith $\mathrm{H}$, Mejdoub $\mathrm{H}$. Microbial production of levansucrase for synthesis of fructooligosaccharides and levan. International journal of biological macromolecules 2012; 50(2): 451-458.

25. Maiorano AE, Piccolo RM, da Silva ES, de Andrade Rodrigues MF. Microbial production of fructosyltranferases for synthesis of prebiotics. Biotechnology letters 2008; 30(11): 1867-1877.

26. Yoo SH, Yoon EJ, Cha J, Lee HG. Antitumor activity of levan polysaccharides from selected microorganisms. International journal of biological macromolecules 2004; 34(1): 37-41.

27. Liu J, Luo J, Ye H, Zeng X. Preparation, antioxidant and antitumor activities in vitro of different derivatives of levan from endophytic bacterium Paenibacillus polymyxa EJS-3. Food and chemical toxicology 2012; 50(3-4): 762-772.

28. Permatasari NU, Ratnaningsih E, Hertadi R. Molecular cloning and expression of levansucrase gene from Bacillus licheniformis BK1 isolated from Bledug Kuwu Mud Crater. EurAsian journal Bioscience 2019; 13: 223-230.

29. Permatasari NU, Ratnaningsih E, Hertadi R. The use of response surface method in optimization of levan production by heterologous expressed levansucrase from halophilic bacteria Bacillus licheniformis BK2.
IOP Conference series: earth and environmental science 2018; 209(1): 012015.

30. Lu L, Fu F, Zhao R, Jin L, He C, Xu L, Xiao M. A recombinant levansucrase from Bacillus licheniformis 837-0-1 catalyzes versatile transfructosylation reactions. Process biochemistry 2014; 49(9): 1503-1510.

31. Xiao-Kui M, Qinqin R, Hong Z, Weidong Q. Developing a high-throughput microassay for large samples of fungal polysaccharides. Analytical methods 2013; 5(17): 4310.

32. Zhang W, Zhang X, Cai L, Chen R, Zhang Q, Wang X. Determination of levan from Bacillus licheniformis by ultraviolet spectrophotometry. Tropical journal of pharmaceutical research 2015; 14(4): 679-685.

33. Molyneux P. The use of the stable free radical diphenylpicryhydrazyl (DPPH) for estimating antioxidant activity. Songklanakarin journal of science and technology 2004; 26(2): 211-219.

34. Noipa T, Srijaranai S, Tuntulani T, Ngeontae W. New approach for evaluation of the antioxidant capacity based on scavenging DPPH free radical in micelle systems. Food research international 2011; 44(3): 798806.

35. Balouiri M, Sadiki M, Ibnsouda SK. Methods for in vitro evaluating antimicrobial activity: A review. Journal of pharmaceutical analysis 2016; 6(2): 71-79.

36. Zhang Y, Wu Y, Zheng W, Han X, Jiang Y, Hu P, Tang $\mathrm{Z}$, Shi L. The antibacterial activity and antibacterial mechanism of a polysaccharide from Cordyceps cicadae. Journal of functional foods 2017; 38(Part A): 273-279.

37. Spanò A, Gugliandolo C, Lentini V, Teresa L, Maugeri, Anzelmo G, Poli A, Nicolaus B. A novel EPSproducing strain of Bacillus licheniformis isolated from a shallow vent off Panarea island (Italy). Current microbiology 2013; 67(1): 21-29.

38. Ahmed KBA, Kalla D, Uppuluri KB, Anbazhagan V. Green synthesis of silver and gold nanoparticles employing levan, a biopolymer from Acetobacter xylinum NCIM 2526, as a reducing agent and capping agent. Carbohydrate polymers 2014; 112: 539-545.

39. Srikanth R, Siddartha G, Sundhar Reddy CH, Harish BS, Janaki Ramaiah M, Uppuluri KB. Antioxidant and anti-inflammatory levan produced from Acetobacter xylinum NCIM2526 and its statistical optimization. Carbohydrate polymers 2015; 123(5): 8-16.

40. Liu Q, Yu S, Zhang T, Jiang B, Mu W. Efficient biosynthesis of levan from sucrose by a novel levansucrase from Brenneria goodwinii. Carbohydrates polymers 2017; 157: 1732-1740.

41. Reyes-Ortega F. In: Aguilar MR, Roman JS, editors. Smart Polymers and Their Applications: ph-Responsive Polymers: Properties, Synthesis and Applications. UK: Woodhead Publishing; 2014. P. 45-92.

42. Cavalcanti OA, Petenuci B, Bedin AC, Pineda EAG, Hechenleitner AAW. Characterisation of ethylcellulose films containing natural polysaccharides by thermal analysis and FTIR spectroscopy. Acta Farmacéutica Bonaerense 2004; 23(1): 53-57.

43. Poli A, Kazak H, Gürleyendağ B, Tommonaro G, Pieretti G, ToksoyÖner E, Nicolaus B. High level 
synthesis of levan by a novel Halomonas species growing on defined media. Carbohydrate polymers 2009; 78(4): 651-657.

44. Benattouche Z, Bouhadi D, Raho GB. Antioxidant and antibacterial of exopolysaccharides. International journal of food studies 2018; 7(2): 30-37.

45. Zhang Z, Jin J, Shi L. Antioxidant activity of the derivatives of polysaccharide extract from a Chinese medical herb (Ramulus mori). Food science and technology research 2008; 14(2): 160-168.

46. Li XL, Thakur K, Zhang YY, Tu XF, Zhang YS, Zhu DY, Zhang JG, Wei ZJ. Effects of different chemical modifications on the antibacterial activities of polysaccharides sequentially extracted from peony seed dreg. International journal of biological macromolecules 2018; 116: 664-675. 